\title{
In Silico Screening of Metal-Organic Frameworks for Adsorption- Driven Heat Pumps and Chillers
}

\author{
Máté Erdős, ${ }^{\dagger}$ Martijn F. de Lange, ${ }^{\dagger}$ Freek Kapteijn, ${ }^{\ddagger}$ Othonas A. Moultos, ${ }^{\dagger}$ and Thijs J. H. Vlugt*, ${ }^{\dagger}$ a \\ ${ }^{\dagger}$ Engineering Thermodynamics, Process \& Energy Department, Faculty of Mechanical, Maritime and Materials Engineering, Delft \\ University of Technology, Leeghwaterstraat 39, 2628CB Delft, The Netherlands \\ ${ }^{\ddagger}$ Catalysis Engineering, Chemical Engineering Department, Faculty of Applied Sciences, Van der Maasweg 9, 2629 HZ Delft, The \\ Netherlands
}

\section{Supporting Information}

ABSTRACT: A computational screening of 2930 experimentally synthesized metal-organic frameworks (MOFs) is carried out to find the best-performing structures for adsorption-driven cooling (AC) applications with methanol and ethanol as working fluids. The screening methodology consists of four subsequent screening steps for each adsorbate. At the end of each step, the most promising MOFs for AC application are selected for further investigation. In the first step, the structures are selected on the basis of physical properties (pore limiting diameter). In each following step, points of the adsorption isotherms of the selected structures are calculated from Monte Carlo simulations in the grand-canonical ensemble. The most promising MOFs are selected on the basis of the working capacity of the structures and the location of the adsorption step (if present), which can be related to the applicable operational conditions in AC. Because of the possibility of reversible pore condensation (first-order phase transition), the mid-density scheme is used to efficiently and accurately determine the location of the adsorption step. At the end of the screening procedure, six MOFs with high deliverable working capacities $(\sim 0.6 \mathrm{~mL}$ working fluid in $1 \mathrm{~mL}$ structure $)$ and diverse adsorption step locations are selected for both adsorbates from the original 2930 structures. Because the highest experimentally measured deliverable working capacity to date for MOFs with methanol is ca. $0.45 \mathrm{~mL} \mathrm{~mL}^{-1}$, the selected six structures show the potential to improve the efficiency of ACs.

KEYWORDS: metal-organic frameworks, adsorption, heat pumps, chillers, Monte Carlo

\section{INTRODUCTION}

Energy consumption worldwide is continuously rising and is predicted to reach approximately $150 \%$ of the current level in 2040. ${ }^{1}$ One-fifth of the total ${ }^{1}$ and $50 \%{ }^{2}$ of the European Union's energy demand is attributed to hot water production and space heating/cooling of buildings. ${ }^{3}$ Although more and more energy is produced from clean low-carbon sources for heating/cooling, $75 \%$ of it is still acquired using fossil fuels. ${ }^{2}$ To tackle the problems of the increasing energy consumption and the considerable use of fossil fuels in energy production, the European Union has set several targets, such as improving the energy efficiency by $20 \%$ and to produce $20 \%$ of the total energy consumption from renewable energy sources by $2020{ }^{2}$

To ameliorate the dependence on fossil fuels and increase energy efficiency, several technologies have emerged recently, utilizing renewable energy sources for heating/cooling applications. ${ }^{4,5}$ Among these, thermally driven heaters and coolers are promising candidates because of the use of thermal energy instead of electricity. ${ }^{6}$ The working principles of these technologies are based on absorption, ${ }^{7}$ chemical reaction, ${ }^{8}$ or adsorption. ${ }^{9}$ One of the advantages of adsorption-driven heat pumps/chillers (AHP/ACs) is the applicability of lowtemperature $(<373 \mathrm{~K})$ heat sources (e.g., solar, industrial waste heat, etc.) as the driving force. ${ }^{10,11}$ Environmentally friendly working fluids, such as water, methanol, or ethanol, can be used. ${ }^{12,13}$ A drawback of AHP/AC systems is the lower performance compared to that of heat pumps based on absorption or chemical reactions. ${ }^{13}$

One possible way to improve the energy efficiency of AHP/ ACs is by finding adsorbents with enhanced adsorption and thermophysical properties. To this extent, several types of materials have been already reported in the literature as possible adsorbents in AHP/AC applications. Such materials are zeolites, silica gels, activated carbons, composite adsorbents, and metal-organic frameworks (MOFs). ${ }^{10,14,15}$ MOFs are crystalline porous materials consisting of metal ions or inorganic clusters connected by organic linkers. ${ }^{16}$ During the last decade, much attention has been drawn to these materials, and more than 60000 different MOF structures have been reported to date. ${ }^{17,18}$ One of the main advantages of MOFs is that they are highly tunable. ${ }^{19}$ By changing the organic linkers and/or metal clusters, specific properties such

Received: June 5, 2018

Accepted: July 19, 2018

Published: July 19, 2018 
as the porosity, pore size, surface area, hydrophilicity, etc. can be altered or embedded to MOFs. Therefore, tailor-made structures with desired properties can be obtained for several technological applications such as catalysis, ${ }^{20}$ gas separation, ${ }^{21}$ or energy storage. $^{22}$ Additionally, several MOFs have stepwise adsorption isotherms, which provides the possibility to operating AHP/ACs over a small pressure range. The high porosity, surface area, exchangeable linkers of the structure and possible stepwise adsorption behavior make MOFs promising candidates as adsorbents in adsorption-driven heat pumps and chillers. $^{13}$

In conjunction with the application of MOFs as adsorbents, alcohols (methanol, ethanol) can be used as promising adsorbates. $^{23}$ It is shown that several MOFs lose structural stability after prolonged exposure to water, an issue that seems to be more severe in the case of ammonia. ${ }^{13,24,25}$ By using methanol or ethanol as the adsorbate, the degradation of the structure is not observed. $^{23,26}$

Because of the relatively high triple-point temperature of water $(273.16 \mathrm{~K}),{ }^{27}$ it cannot be used for cooling applications below $0{ }^{\circ} \mathrm{C}$. Methanol and ethanol have lower triple-point temperatures (methanol: $175 \mathrm{~K}$, ethanol: $150 \mathrm{~K})^{28,29}$ and are applicable below $0{ }^{\circ} \mathrm{C} .{ }^{23}$ Because alcohols have a higher vapor pressure than that of water, the adsorption-desorption cycle is expected to be more efficient. ${ }^{30}$ At the operating conditions of AHP/ACs, alcohols have lower enthalpy of evaporation (at $303 \mathrm{~K}$ and 1 bar: methanol $\sim 0.90 \mathrm{~kJ} \mathrm{~mL}^{-1}$, ethanol $\sim 0.65 \mathrm{~kJ}$ $\left.\mathrm{mL}^{-1}\right)^{31}$ compared to that of water (at $303 \mathrm{~K}$ and 1 bar: $\sim 2.30$ $\left.\mathrm{kJ} \mathrm{mL}{ }^{-1}\right) .{ }^{31}$ Therefore, the allocatable amount of heat/cold with the same volume of adsorbed material is lower for alcohols. Although alcohols possess several advantageous properties compared with other adsorbates, adsorbents with a higher alcohol adsorption capacity $(>0.45 \mathrm{~mL}$ working fluid per $1 \mathrm{~cm}^{3}$ structure $)^{23,32}$ have to be developed for more efficient application of alcohols in AHP/ACs. ${ }^{23}$

For the design of more efficient AHP/ACs and fundamental understanding of the structure-adsorption behavior relationships, a large sample of structures should be examined. Because of the enormous number of possible MOFs, an experimental screening for AHP/AC purposes is not feasible. Fortunately, modern computational methods make it viable to investigate a large number of structures and identify the superior candidates for the desired application. Over the last decade, several highthroughput screening studies have been published for various applications of MOFs such as gas separation $\left(\mathrm{SO}_{2} / \mathrm{NO}_{x}, \mathrm{CO}_{2} /\right.$ $\mathrm{CH}_{4}, \mathrm{CO}_{2} / \mathrm{N}_{2}, \mathrm{CH}_{4} / \mathrm{H}_{2}$, hexane isomers), ${ }^{33-37} \mathrm{CO}_{2}$ capture, ${ }^{38,39} \mathrm{CH}_{4}$ adsorption, ${ }^{40}$ and enantioselective adsorption. ${ }^{41}$ These screening studies investigate adsorption of gases at conditions where the phenomena of pore condensation can be neglected. At the operating conditions of AHP/ACs with MOFs, pore condensation can occur, which causes the stepwise adsorption behavior. Pore condensation involves first-order phase transition of the adsorbate. To the best of our knowledge, there is no reported computational screening study of MOFs involving the phenomenon of pore condensation.

To conduct a computational screening study of MOFs, a database of computation-ready structures (e.g., solvent-free, no disordered atoms) is desirable. In the case of MOFs, the Computation-Ready, Experimental (CoRE) database is accessible, containing data for more than 4700 structures. ${ }^{42}$ This database has been extended, for most of the MOFs ( 3000), with accurate point charges, computed by the density-derived electrostatic charges (DDECs) method ${ }^{43}$ (in this study referred to as DDEC database). This extension makes CoRE able to describe the electrostatic interactions during the adsorption process. ${ }^{43}$ Electrostatics plays a crucial role when studying the adsorption of polar molecules (for example alcohols) in MOFs. ${ }^{35,44}$

In this screening study, Monte Carlo simulations are performed in various statistical ensembles to select the best MOFs from the DDEC database for AC application. To the best of our knowledge, this is the first screening study of MOFs that involves the phenomenon of pore condensation. For both methanol and ethanol, four screening steps are carried out leading to the six best structures, from the initial $\sim 2930$, at the end of the screening process. The selected 12 structures ( 6 for each adsorbate) show diverse adsorption step locations and promisingly high deliverable working capacities $(\sim 0.6 \mathrm{~mL}$ $\mathrm{mL}^{-1}$ ) compared with the experimentally reported highest values $\left(\sim 0.45 \mathrm{~mL} \mathrm{~mL}^{-1}\right){ }^{32}$ These materials are promising candidates as adsorbents for AHP/ACs because the diverse adsorption step location allows for different operational conditions and the high working capacities provide an opportunity for more allocatable heat/cold per working cycle.

This article is structured as follows. In Section 2, the chosen database and the devised screening process are explained in detail. In Section 3, the details of the performed simulations are reported. In Section 4, the results of the screening steps with explanation are presented. In Section 5, the summary and conclusions of the screening study are presented.

\section{DATABASE AND SCREENING METHODOLOGY}

To conduct a computational screening study of MOFs, a database of computation-ready structures (e.g., solvent-free, no disordered atoms) is desirable. ${ }^{42}$ Regarding the composition of the database, diverse types of structures with a broad range of structural properties are desired.

2.1. Database. Computational screening studies of MOFs are usually conducted using database containing hypothetical MOFs. ${ }^{45-51}$ Although such an approach can provide insight into structure-property relationships, it is possible that the promising structures cannot be synthesized. To this end, in this study, a database of already experimentally synthesized structures is used. As already mentioned in the Introduction, the CoRE database ${ }^{42}$ contains ca. 4700 already synthesized MOFs, which are directly usable for simulations. In the computation of adsorption isotherms of polar molecules in MOFs, electrostatic interactions play a major role. Electrostatic interactions are calculated using partial charges provided for each atom. Although polarization effects can play a crucial role in the simulation of polar adsorbate adsorption in MOFs, ${ }^{52,53}$ there is no transferable polarizable force field available for MOFs. Because the derivation of a polarizable force field for each structure would require a considerable amount of time, the polarizability of the system is usually not considered in high-throughput screening studies of MOFs. All assigned partial charges are static in each simulation. The CoRE database has been extended for most of the MOFs ( 3000) with point charges computed by the density-derived electrostatic charges (DDECs) method. ${ }^{43}$ The structures investigated in this screening study are taken from the DDEC database. ${ }^{43}$ There are several duplicates in the database, such as CuBTC that appears $\sim 60$ times with slightly different structures, but more than ca. 2000 structures are unique. ${ }^{43}$ The large structural diversity of the database can be seen by considering that there are more than $\sim 50$ types of metal clusters present in 


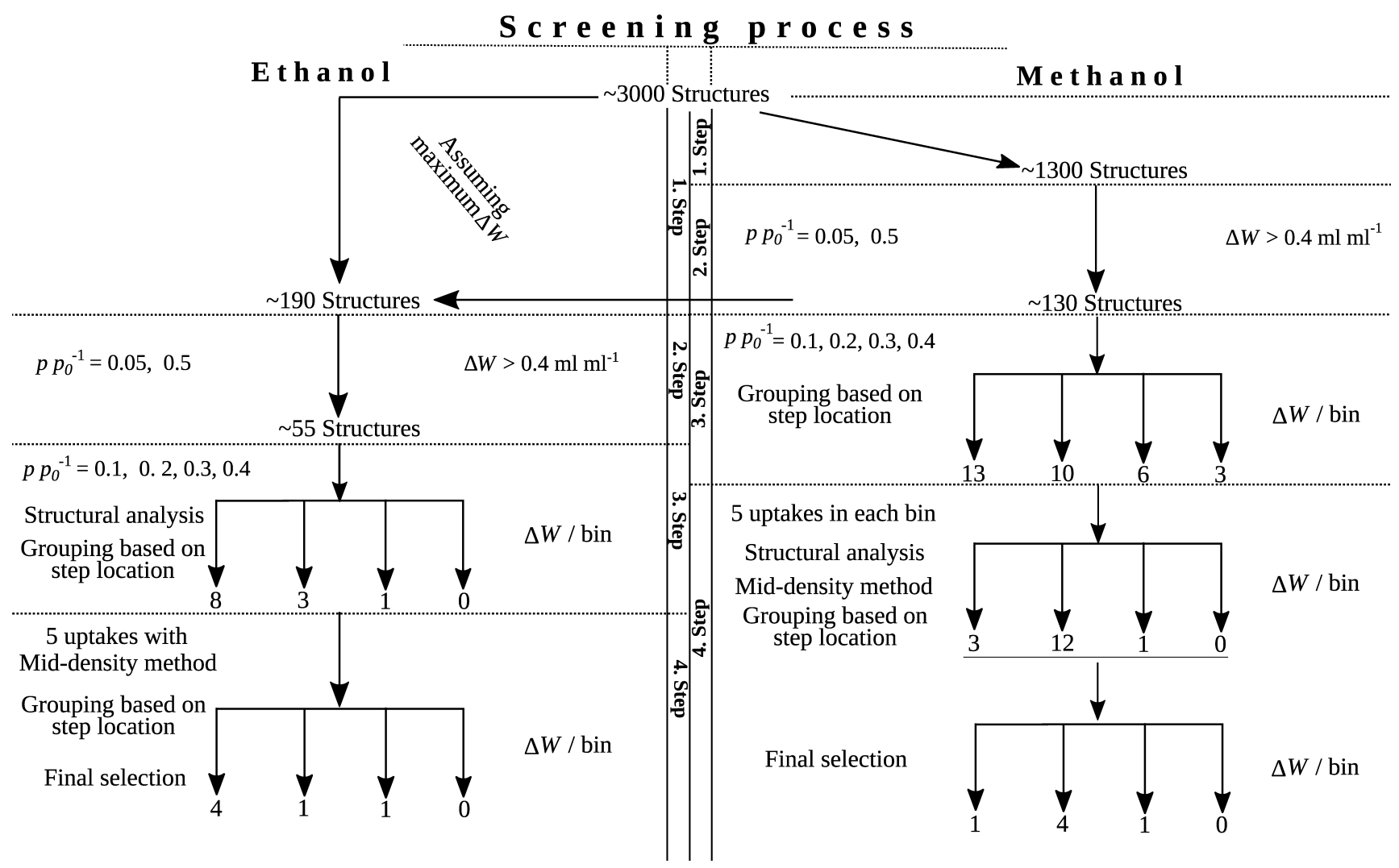

Figure 1. Overview of the devised screening process with methanol and ethanol. For each adsorbate, four subsequent steps are carried out. In the first step with ethanol as the working fluid, the results of the first and second steps with methanol are used to select structures for ethanol. The number of selected structures at the end of each step are shown for each adsorbate. The performed tasks (left side of the step) and the selection criterion (right side of the step) are also shown for each step.

the database. ${ }^{43}$ The structures have pore limiting diameters (PLDs) ranging from $\sim 1$ to $\sim 23 \AA$ and largest cavity diameters (LCDs) from $\sim 2$ to $\sim 24 \AA$. There are only three structures in the database with LCD larger than $\sim 16 \AA$, and the rest of the structures mostly have LCD below $\sim 9 \AA$. One of the unfavorable phenomena in AHP/ACs is the irreversible capillary condensation of the adsorbate, which causes high desorption temperature. Capillary condensation is considered thermodynamically irreversible if an adsorption-desorption hysteresis (i.e., the isotherms for adsorption and desorption are different) occurs. Below the critical pore diameter $\left(D_{\mathrm{C}}\right)$, which can be different for each adsorbate (for methanol, $D_{\mathrm{C}}=35 \AA$, and for ethanol, $\left.D_{C}=43 \AA\right),{ }^{13}$ capillary condensation can be considered reversible (no adsorption-desorption hysteresis). Hence, by considering the available pore diameters range in the database, it becomes apparent that the critical pore diameter for methanol and ethanol are larger than the highest LCD value in the database. Therefore, capillary condensation can be neglected during the screening process.

2.2. Screening Methodology. The objective of this screening study is to select the best-performing MOFs for AC application from the structures available in the DDEC database, in the least amount of computational time possible. Desirable structures should have a very steep adsorption step within the relative pressure $\left(p / p_{0}\right.$, where $p_{0}$ is the saturation pressure of the adsorbate) interval $0.05<p / p_{0}<0.4$ and deliverable working capacity as high as possible. A very steep uptake step is desired to ensure the highest thermodynamic efficiency in AHP/AC application. ${ }^{9,13}$ Because the deliverable working capacity determines the maximum amount of allocatable heat per working cycle, it should be as high as possible. In efficient AC applications, a high regeneration (desorption) temperature is unfavorable because it decreases the efficiency of the cooler. As the working capacity does not depend on the desorption temperature, the desorption isotherms are not considered in this study. An adsorption step at low relative pressure $\left(p / p_{0}<0.05\right)$ can indicate high adsorption affinity, which requires high temperature for regenerating the adsorbent. To avoid high desorption temperatures, the adsorption step should occur at a relative pressure higher than $p / p_{0}=0.05$. ${ }^{9}$ With the adsorption step occurring at higher relative pressures, the temperature difference between the low- (evaporator)- and intermediate (adsorber/condenser)-temperature sides (temperature lift) decreases, resulting in lower efficiency. ${ }^{13}$ To realize a sufficiently high temperature lift, the uptake step should take place below $p / p_{0}=0.4$. $^{9}$ Hence, the desired relative pressure range for methanol and ethanol (for other working fluids, the interval can differ) is 0.05 $<p / p_{0}<0.4$.

Because the calculation of one uptake value of a methanol adsorption isotherm can take days, the simulation of detailed isotherms for $\sim 3000$ structures is not practical. A screening methodology consisting of subsequent steps is devised. In each step, the structures are narrowed down to promising ones on the basis of more and more relevant properties for $\mathrm{AC}$ application. After carrying out the four steps, six MOFs for each adsorbate are chosen as the best-performing structures for AC applications. A schematic representation of the screening process is shown in Figure 1. In the screening process, all 
isotherms are calculated at $303 \mathrm{~K}$ because this is a commonly used adsorption temperature in AC applications. ${ }^{13}$

On the basis of previous studies, ${ }^{13,23}$ methanol and ethanol are expected to show similar adsorption properties. This can be understood by considering the similar structural and chemical properties (e.g., size, $-\mathrm{OH}$ group, etc.) of the two adsorbates. To reduce the computational cost, the results obtained for methanol are also used in the screening process with ethanol. Therefore, methanol is considered first as the adsorbate. After performing the second screening step, the investigation for ethanol is commenced using the results obtained from the first and second screening steps of methanol screening. The detailed description of the screening methodology is presented below.

Because all steps, except for the first, are identical for both adsorbates, the screening process is presented for methanol, and only the first step is presented for screening with ethanol.

Methanol: Step 1: On the basis of the physical properties of the structures and methanol, several MOFs can be excluded. One selection criterion is determined by the kinetic diameter of methanol, which is approximately $3.6 \AA$. During the adsorption-desorption process, molecules have to diffuse into the pores (enter and leave). Hence, structures with the pore limiting diameter less than $4 \AA$ are not considered further. As the pore size of these structures is at least $4 \AA$, we do not expect large barriers for diffusion.

Step 2: For the remaining structures after the first step, two data points of the adsorption isotherm are calculated to determine the difference in the amount of adsorbed working fluid at the two relative pressures (working capacity). Because the adsorption step should take place at the relative pressure window of $0.05<p / p_{0}<0.4,^{13}$ the two uptakes are calculated at relative pressure $p / p_{0}=0.05$ and 0.5 .

Because a significant drawback of the current AHP/ACs is the considerably large size of these devices, ${ }^{13}$ it is desired to find adsorbents that can store more working fluid per unit volume of adsorbent. Therefore, in this work, the loadings are calculated as the volume of the adsorbed material per unit volume of the structure instead of per unit mass. The selection criteria are also defined in this form. To calculate the volume of the structures, the crystallographic densities of the MOFs are used as reported in the database. In the case of the adsorbed material, its volume is approximated using its liquid phase density. The loading $q$, in units of milliliters of adsorbed material per milliliters of adsorbent, can be expressed as

$$
q=\frac{q_{\mathrm{mol}} M_{\mathrm{MeOH}} \rho_{\mathrm{struc}}}{\rho_{\mathrm{MeOH}}^{\mathrm{liq}}}
$$

where $q_{\mathrm{mol}}$ is the loading expressed in units of $\mathrm{mol} \mathrm{kg}{ }^{-1}, \rho_{\text {struc }}$ is the crystallographic density of the framework, $\rho_{\mathrm{MeOH}}^{\mathrm{liq}}$ is the liquid density of methanol (at $T=303 \mathrm{~K}$ and $p=1$ bar, = $\left.781.77 \mathrm{~kg} \mathrm{~m}^{-3}\right),{ }^{54}$ and $M_{\mathrm{MeOH}}$ is the molecular weight of methanol $\left(M_{\mathrm{MeOH}}=0.03204 \mathrm{~g} \mathrm{~mol}^{-1}\right)$.

Structures are selected on the basis of the loading difference between the two calculated points (working capacity, $\Delta W$ ). Because the aim of this study is to contribute to the development of better adsorbents for AC application, the selection criterion is set to $\Delta W>0.4 \mathrm{~mL} \mathrm{~mL}^{-1}$, which is almost the highest already reported working capacity for MOFs $\left(\sim 0.45 \mathrm{~mL} \mathrm{~mL}^{-1}\right)$. $^{32}$

Step 3: To predict the location of the assumed adsorption step, another set of uptakes are calculated for the previously selected structures. The new data points are computed at relative pressures $0.1,0.2,0.3$, and 0.4 for every structure. From the uptakes, the deliverable working capacity $\left(\Delta W_{\text {del }}\right)$ is calculated. $\Delta W_{\text {del }}$ is defined as the highest difference in loading between two adjacent relative pressure points. Relative pressure intervals, where the assumed adsorption step occurs, can be defined by considering the deliverable working capacities. On the basis of the position of the assumed adsorption step, the structures are grouped into four bins:

1. First bin: $\Delta W_{\text {del }}$ is in the range $0.05 \leq p / p_{0} \leq 0.1$

2. Second bin: $\Delta W_{\text {del }}$ is in the range $0.1<p / p_{0} \leq 0.2$

3. Third bin: $\Delta W_{\text {del }}$ is in the range $0.2<p / p_{0} \leq 0.3$

4. Fourth bin: $\Delta W_{\text {del }}$ is in the range $0.3<p / p_{0} \leq 0.4$

Because the evaporator temperature in AHP/AC application depends on the location of the adsorption step, the structures in different bins can be considered for different working conditions in AHP/AC. For example, if the adsorption step occurs at lower relative pressure $p / p_{0}$, a lower evaporator temperature can be applied. Hence, the selection is performed by comparing the deliverable working capacities of the structures in the same bin.

Step 4: In this step, initially the structures are assessed on the basis of structural properties (in the case of ethanol, this information is already used in step 3). The considered properties are the cluster type, ligand type, functional groups, presence of coordinatively unsaturated sites, and pore dimensionality. MOFs with expensive, difficult synthesis routes or with potentially harmful building blocks are not desirable for the application. The flexibility of the structure can cause desorption hysteresis, ${ }^{13}$ which increases the desorption temperature and lowers the efficiency. Therefore, frameworks with expensive/difficult synthesis, potentially harmful building blocks, or flexibility are not considered further. To determine the presence and location of the adsorption step, five more uptake values of the isotherm are calculated for the above selected structures at relative pressures linearly distributed over the interval of the bin assigned to the structure. In these simulations, the mid-density scheme ${ }^{55}$ (briefly explained in Section 3) is applied to accurately locate the adsorption step.

Using the results of these simulations, the final selection is made. The six best structures are selected on the basis of the deliverable working capacity and the location of the adsorption step.

Ethanol: Step 1: As mentioned earlier, the first selection criterion in the case of ethanol differs from that for methanol. By considering the similar adsorption behavior of methanol and ethanol and using the results obtained for methanol adsorption (steps 1 and 2), a significant amount of computational time can be saved.

In the case of ethanol adsorption, the following groups of structures can be distinguished:

1. Low uptake at $p / p_{0}=0.05$, high uptake at $p / p_{0}=0.5$

2. High uptake at $p / p_{0}=0.05$, high uptake at $p / p_{0}=0.5$

3. Low uptake at $p / p_{0}=0.05$, low uptake at $p / p_{0}=0.5$

The groups that contain structures with potentially high working capacity for ethanol can be identified by assuming similar adsorption behavior for the two working fluids. This assumption is that if methanol shows a stepwise adsorption behavior then ethanol behaves alike and the adsorption step also occurs for ethanol but at a lower relative pressure (Figure 2 shows the schematic representation of this assumption). The validity of this assumption is based on the experimental work 


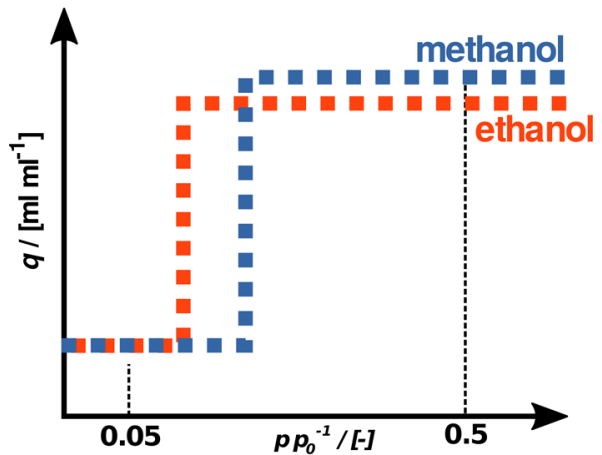

Figure 2. Schematic representation of the adsorption behaviors of methanol and ethanol. If methanol shows a stepwise adsorption isotherm with a MOF, then ethanol behaves alike and the adsorption step also occurs for ethanol but at a lower relative pressure.

reported in ref 23 and by considering the stronger confinement effects caused by the bigger size of the ethanol molecules. ${ }^{23} \mathrm{On}$ the basis of this assumption, the group of structures that can be suitable for ethanol adsorption is identified.

In the case of the first group, the structures have an adsorption step for methanol with working capacity higher than $0.4 \mathrm{~mL} \mathrm{~mL}^{-1}$. This means that for ethanol the adsorption step also occurs and shifts to a lower relative pressure. Therefore, these structures are considered as potential candidates for ethanol adsorption as well. The third group can also contain structures with high working capacity, based on the assumption that the adsorption step of these structures for methanol would occur at higher relative pressures than 0.5 and would shift to lower relative pressures in the case of ethanol. Therefore, these structures can be favorable with ethanol. Because the structures in the second group are already saturated at $p / p_{0}=0.05$, these MOFs are not desirable in the screening with ethanol. On the basis of the working capacity values, structures in the second and third groups cannot be distinguished. To select the promising structures from these groups, the highest achievable working capacity with ethanol as the working fluid is approximated. By examining the results obtained for methanol (Figure 3 ) and based on the kinetic diameter of helium $(\sim 2.6 \AA)$ and methanol $(\sim 3.6 \AA)$, the following assumptions are made: $85 \%$ of the calculated helium void fraction can be used for alcohols as free volume for adsorption. The free space left after methanol adsorption at the highest simulated relative pressure is calculated as follows

$$
E_{\mathrm{v}}=0.85 \phi^{\mathrm{He}}-q_{0.5}^{\mathrm{MeOH}}
$$

where $E_{\mathrm{v}}$ is the empty void volume after methanol adsorption at $p / p_{0}=0.5, \phi^{\mathrm{He}}$ is the helium void fraction of the structure, and $q_{0.5}^{\mathrm{MeOH}}$ is the methanol uptake at relative pressure $p / p_{0}=$ 0.5 . The highest possible working capacity with ethanol as the working fluid is calculated as follows

$$
\Delta W_{\max }^{\mathrm{EtOH}}=\Delta W^{\mathrm{MeOH}}+E_{\mathrm{v}}
$$

This equation is used to predict the highest achievable working capacity with ethanol as the adsorbate, for all of the structures considered in the second step of the screening with methanol. The selection is carried out by considering the predicted maximum ethanol working capacity of the structures that are selected for the second screening step with methanol. Structures with the predicted working capacity higher than (a)

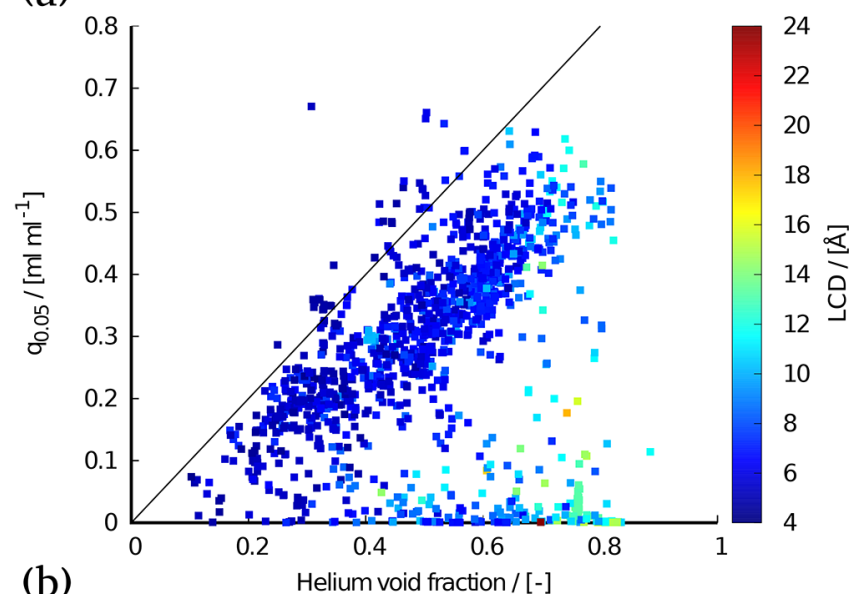

(b)
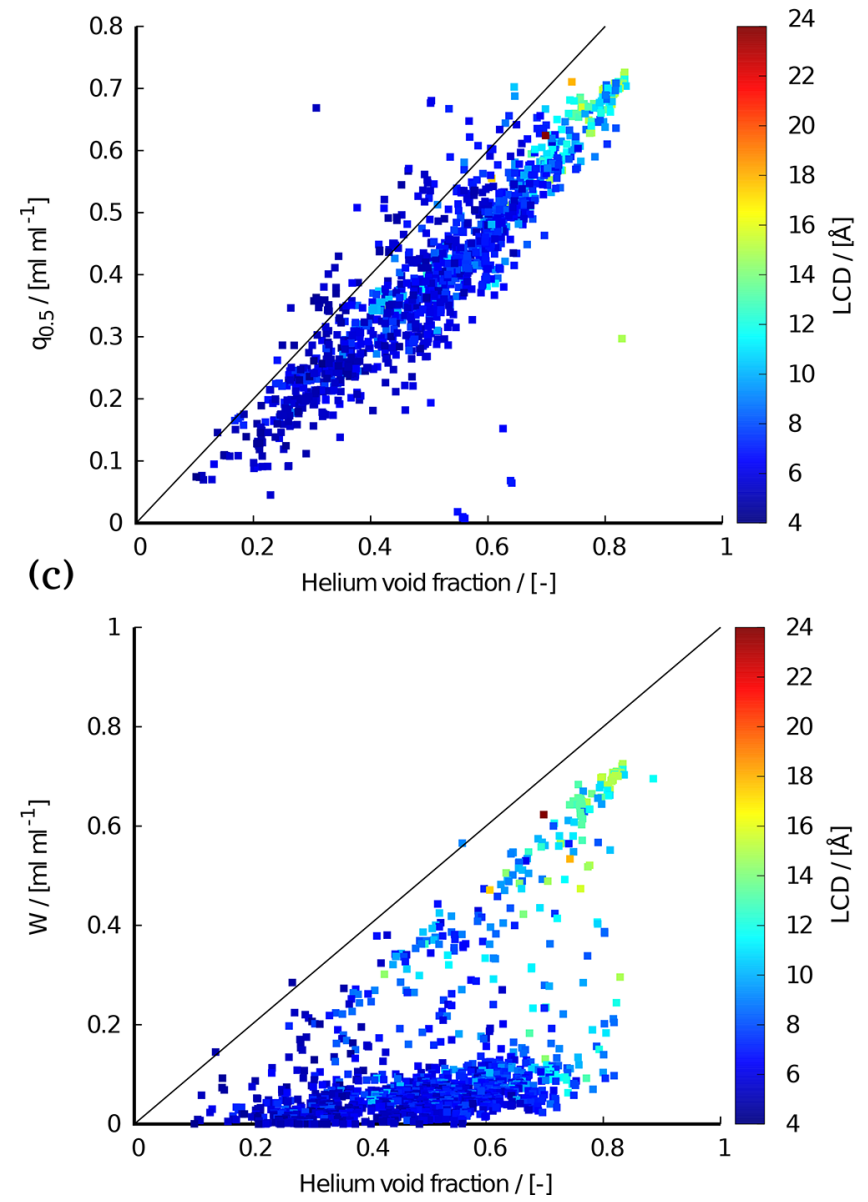

Figure 3. Excess adsorption uptake at relative pressure $p / p_{0}=0.05$ (a) and $p / p_{0}=0.5$ (b) and working capacity (c) with methanol as a function of the helium void fraction for the ca. 1300 structures considered in the second step at $303 \mathrm{~K}$ (where $p_{0}$ is the experimentally measured saturation pressure of the adsorbate, $p_{0}=$ $21.70 \mathrm{kPa}){ }^{86}$ The coloring represents the largest cavity diameter (LCD) of the structures.

$0.4 \mathrm{~mL} \mathrm{~mL} \mathrm{~m}^{-1}$ are chosen for the subsequent screening step (step 2).

\section{SIMULATION DETAILS}

All Monte Carlo simulations are carried out with the RASPA software package. ${ }^{56,57}$ The force-field parameters for adsorbates are taken from the TraPPE force field. The adsorbates 
(a)

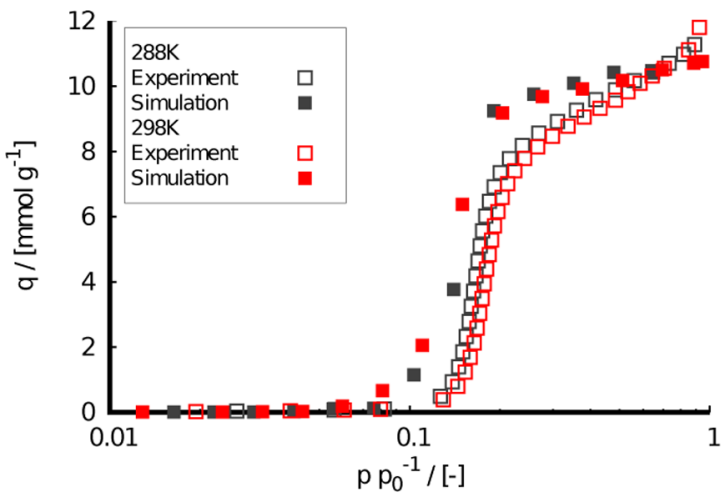

(b)

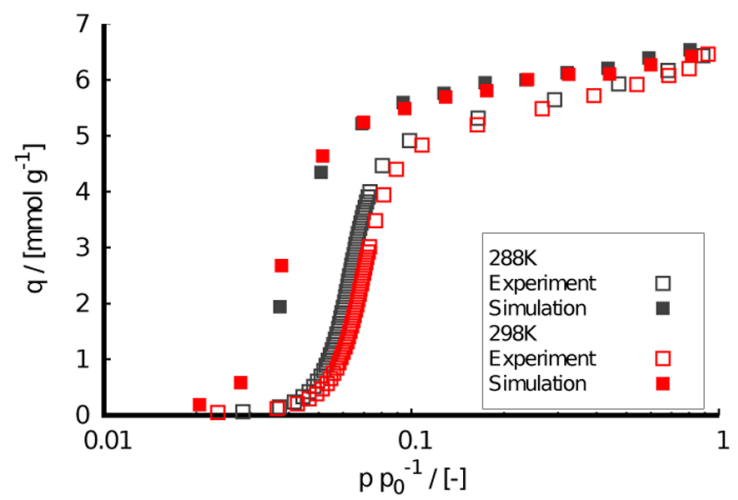

Figure 4. Excess amounts of adsorbed methanol (a) and ethanol (b) as a function of relative pressure, $p / p_{0}$ (where $p_{0}$ is the experimentally measured saturation pressure of the adsorbate), for ZIF- 8 at $288 \mathrm{~K}$ (for methanol $p_{0}=9.80 \mathrm{kPa}$, for ethanol $\left.p_{0}=4.28 \mathrm{kPa}\right)^{86}$ and $298 \mathrm{~K}$ (for methanol $p_{0}=16.81 \mathrm{kPa}$, for ethanol $\left.p_{0}=7.82 \mathrm{kPa}\right){ }^{86}$ Closed symbols represent simulation results, and open symbols are experimental data. ${ }^{23}$

(methanol, ethanol) are simulated as flexible molecules. The bond lengths are fixed, but bond bending angles and dihedrals are used. The Lennard-Jones $(\mathrm{LJ})$ parameters of the MOFs are primarily taken from the DREIDING force field, and for the parameters that are not available, the parameters reported in the UFF force field are used. Short-range van der Waals interactions are taken into account by the (12-6) LennardJones potential. Long-range electrostatic interactions are considered by the Ewald summation method with a relative precision of $10^{-6}$. For the LJ interactions, a cutoff radius of 14 $\AA$ is applied. As the TraPPE force field uses tail corrections, we applied these to all Lennard-Jones interactions. The mixed pair potentials are calculated using the Lorentz-Berthelot mixing rule. ${ }^{58}$ In all MC simulations, periodic boundary conditions are imposed in every direction. The atomic charges of the structures are taken from the crystallographic files published in the aforementioned database. All force-field parameters are listed in Tables S1 and S2 in the Supporting Information along with the appropriate references.

The size of the simulation box is determined by the number and size of the unit cells. In each simulation, the number of unit cells per simulation box is chosen on the basis of the defined cutoff radius. The length of the simulation box in each direction is at least twice the cutoff radius. The frameworks are considered rigid in all simulations. This approach is often applied in simulations of nanoporous materials to prevent the necessity of excessive computational efforts. ${ }^{59}$

To obtain the adsorption isotherms of methanol and ethanol in the different MOF structures, configurational-bias Monte Carlo (CBMC) simulations $^{60}$ in the grand-canonical $(\mu V T)$ ensemble $^{60}$ are used. In these simulations, the temperature; chemical potential, which can be related to pressure (for example by using the Peng-Robinson equation of state); and the volume of the simulation box are kept constant. The following types of trial moves are used: translations $(\sim 18 \%)$, rotations $(\sim 18 \%)$, reinsertions $(\sim 10 \%)$, partial reinsertions/ deletions $(\sim 18 \%)$, and molecule exchanges with the reservoir ( 36\%).

To create initial configurations with predefined states (e.g., amount of adsorbates in the framework) for the GCMC simulation, the CBMC simulation technique in the canonical ensemble $(N V T)$ is used. In these simulations, the temperature, the volume, and the number of particles are kept constant. The following types of trial moves were applied: translations $(25 \%)$, rotations $(25 \%)$, reinsertions $(25 \%)$, and partial reinsertions (25\%).

All simulations started with an equilibration period of 50 000-500000 cycles in which ensemble averages are not calculated. In a cycle, the number of MC steps is equal to the number of molecules in the simulation box with a minimum of $20 \mathrm{MC}$ steps per cycle. In this study, to obtain sufficiently accurate results, each simulation is restarted until the standard deviation of the number of adsorbed molecules $(\mu V T)$ or the total energy of the system (NVT) becomes smaller than $5 \%$. Hence, the number of cycles is not specified in this description because it can differ from structure to structure and also for pressures. In general, 50 000-500 000 cycles are applied in the simulations. Although in this article excess uptakes are shown, it is important to note that in the investigated pressure range the calculated absolute and excess uptakes are nearly identical.

Certain geometric properties of the structures are required to conduct the screening study. The helium void fraction for each MOF structure is calculated with the Widom insertion method. ${ }^{56}$ The pore limiting diameter (PLD), largest cavity diameter (LCD), and the volumetric surface area (VSA) of each structure are calculated in the first step of the screening study. These simulations are performed using the Zeo++ software package. ${ }^{61}$

3.1. Mid-Density Scheme. At relative pressures close to a high change in the density of the adsorbed phase (such as close to a steep adsorption step), the simulation of uptakes can be difficult because of the presence of metastable states. To determine the accurate location of the equilibrium phase transition, in principle, thermodynamic integration of the grand potential can be used. ${ }^{62,63}$ However, this method is computationally expensive. To overcome this problem, a computationally cheaper method, the mid-density scheme, ${ }^{55}$ can be applied to determine the accurate location of the equilibrium phase transition.

In this method, three isotherms are calculated: one isotherm with an empty (considered as the default initial configuration in this work), one with a saturated, and one with a "half"saturated simulation box as initial configurations. After obtaining the first two isotherms (from empty and saturated initial box), usually a hysteresis can be observed. In the case of a hysteresis, for one relative pressure, two states are found. One of the states is a metastable state, and the another is a stable state. These two states are separated by free energy barrier (a 


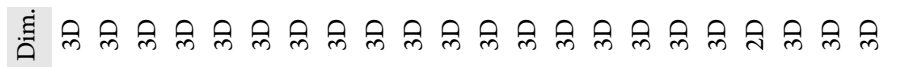

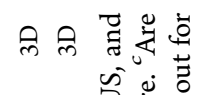

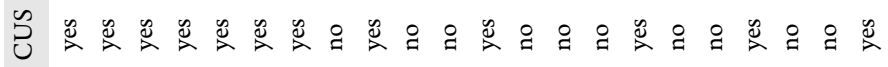

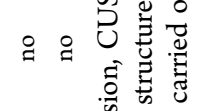

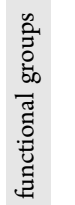

苛

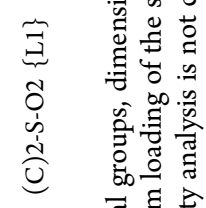

竞

突

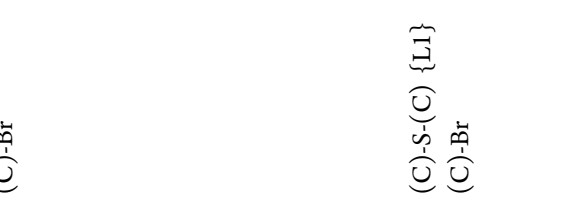

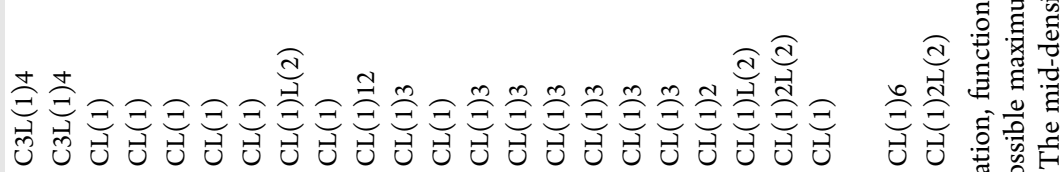

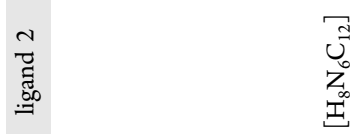

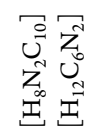

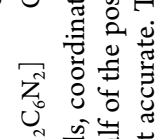

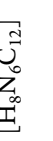

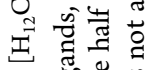

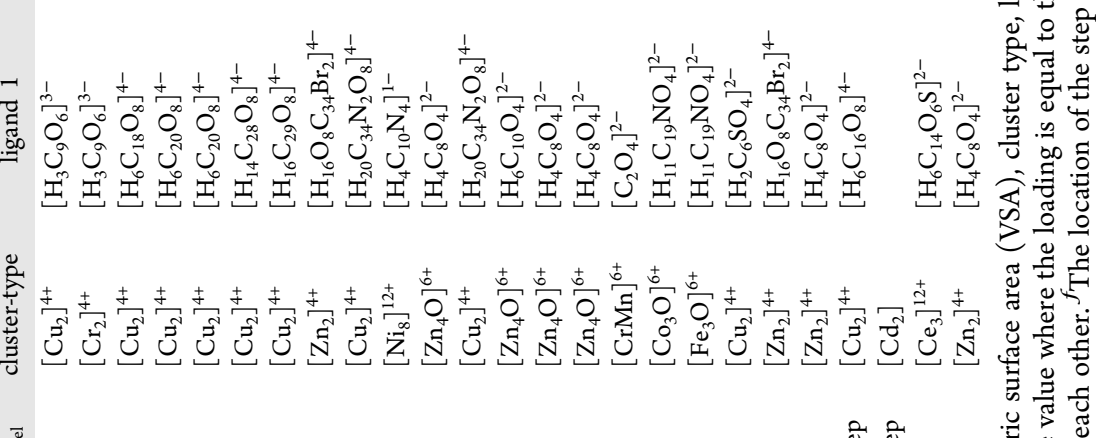

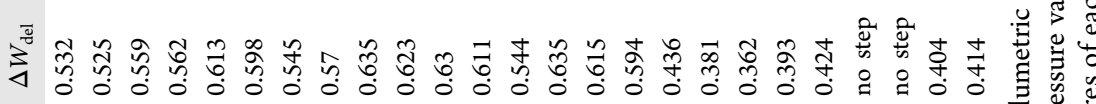

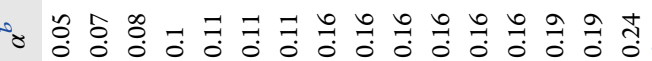

'

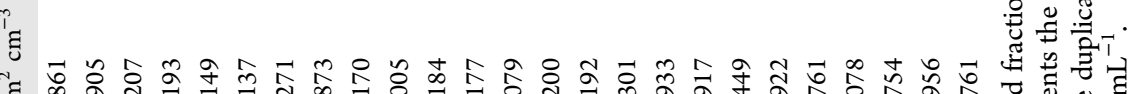

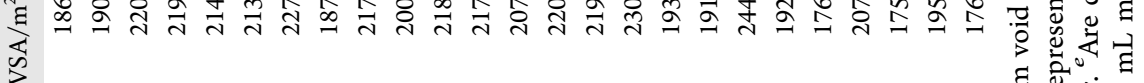

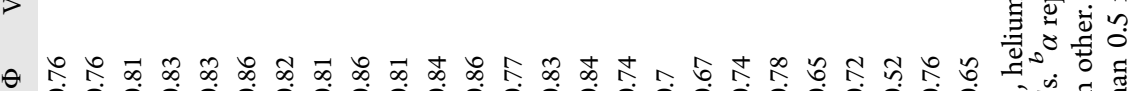

$\theta$ 然

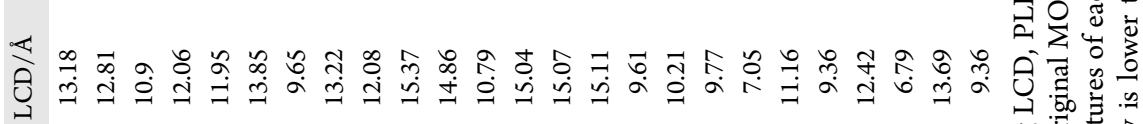

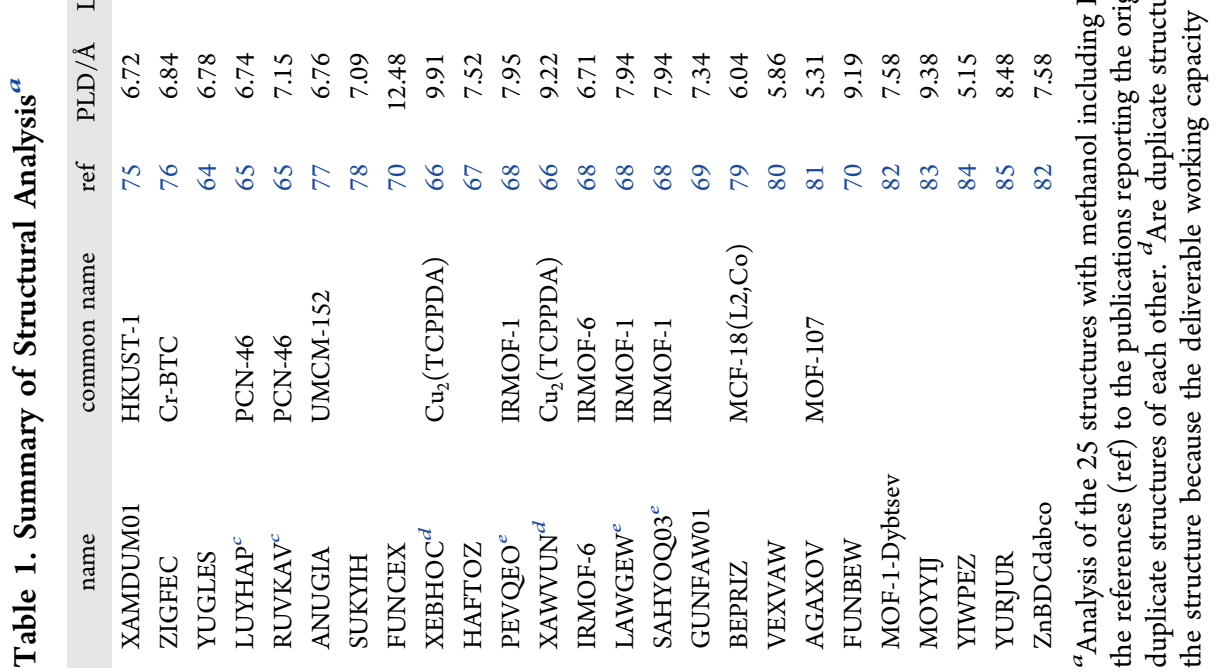


saddle point in the number of particles-relative pressure space). To identify the stable state, the simulations are started with the average loading (see Figure S19 in the Supporting Information in which the three calculated adsorption isotherms with methanol for the PEVQEO structure are shown). For each average number of adsorbed molecules, an NVT simulation is performed. The results of these NVT simulations are used as new initial configurations (half-saturated box) in GCMC simulations performed at the corresponding relative pressures where the two calculated loading values (from initially empty and saturated) differ from each other. The obtained isotherm from the simulations with the half-saturated box as the initial configuration is considered to represent the accurate adsorption step.

\section{RESULTS AND DISCUSSION}

Because there is no specific and transferable force field for alcohol adsorption in MOFs, the applicability of the chosen force field has to be tested. To validate the force field, experimentally measured isotherms of methanol and ethanol are compared with the isotherms obtained from the simulations. In the database, six structures with available experimental adsorption data for either methanol or ethanol exist. Therefore, these structures are used for the validation of the force field. In the DDEC database, the naming of the structures is mixed. Most of the structures are referred to with a combination of six letters (for example DOTSOV), and some of the frameworks are reported with common names, e.g., ZIF8, ZIF-90, etc. For consistency, the exact reported names in the database are used here. In Figure 4, the experimentally measured and simulated adsorption isotherms with methanol and ethanol as adsorbates at 288 and $298 \mathrm{~K}$ are shown for ZIF8. When $p / p_{0}$ approaches 1 , a step in the experimental isotherm is observed; see Figure 4. This may be due to condensation on the outside of the crystal or in the interparticle space, especially when small particles or powders are used in the experiments. As this occurs outside the range of the pressures relevant for our application, we did not studied this further. The experimentally measured and simulated isotherms for the other five structures are shown in the Supporting Information. Although the applied generic force field has not been specifically fitted to reproduce these experiments, the experimental and simulation results are in reasonable agreement. On the basis of the results obtained for the six structures used in the validation, it is concluded that the location of the adsorption step (if present) and the uptake values are properly captured by the proposed force field.

4.1. Screening with Methanol. In this section, the results of each screening step with methanol are presented. By excluding structures with PLD $<4 \AA$ (step 1), approximately 1300 from the original 2930 structures are selected for step 2 .

In Figure 3, the adsorbed amounts of methanol at relative pressures $p / p_{0}=0.05$ and 0.5 and the working capacity are plotted as a function of the helium void fraction for the selected ca. 1300 structures (step 2). The color code represents the largest cavity diameters of the structures. In Figure 3a,b, methanol adsorption values at the lower $\left(p / p_{0}=\right.$ $0.05)$ and higher $\left(p / p_{0}=0.5\right)$ relative pressures are shown, respectively. Most of the structures with the LCD lower than $\sim 10 \AA$ are already saturated at $p / p_{0}=0.05$. Almost all structures are nearly or fully saturated at $p / p_{0}=0.5$ (Figure $3 \mathrm{~b})$. The structures showing high working capacities are mainly the ones with a higher LCD (>10 A) (Figure 3c). This finding indicates the strong correspondence between the adsorption uptake value at the lower relative pressure and the working capacity of the structure. It is observed (Figure 3) that for structures with pore diameters smaller than ca. $16 \AA$ the most critical parameter determining the working capacity is the uptake of the structure at $p / p_{0}=0.05$. Unfortunately, the DDEC database contains only three structures with LCDs higher than $16 \AA$. Therefore, the possibilities to investigating the effect of the pore dimensions on the adsorption uptake are limited.

On the basis of the calculated working capacities of the structures, 159 MOFs fulfill the selection criterion $(\Delta W>0.4$ $\left.\mathrm{mL} \mathrm{mL} \mathrm{L}^{-1}\right)$. Among these, there are multiple structures that are practically the same (chemical composition, underlying topology, etc.) with slight differences in the atomic positions. These structures are referred to as duplicates, and most of these are excluded from the screening. A few duplicates are used in this study to investigate the sensitivity of the method to small structural differences. Some of these duplicates are shown in Table 1 and Figures S8-S18. Consequently, the number of structures selected for the subsequent step is 130 .

The four additional points of the isotherm are calculated for each selected structure. On the basis of the obtained results, the structures are grouped according to the defined "bin" system. The cardinalities of the 1st, $2 \mathrm{nd}, 3 \mathrm{rd}$, and 4 th bin are $69,31,26$, and 4, respectively. The obtained adsorption isotherms are shown in the Supporting Information. There are 40 structures with lower deliverable working capacity than the desired $0.4 \mathrm{~mL} \mathrm{~mL}^{-1}$. This is an indication for a non-stepwise adsorption behavior, and these structures are not considered for further investigation (e.g., NEDWAW structure in Figure S13 in the Supporting Information). For the next screening step, 13 structures from the first bin, 10 from the second, 6 from the third, and 3 structures from the fourth bin with the highest deliverable working capacities are selected. Because it is not straightforward how to handle duplicated structures, in each case, the duplicates with the highest and with the lowest deliverable working capacities are chosen to investigate the difference.

On the basis of the structural assessment of the selected structures, several structures are discarded. BICDAU, ECOLEP, and HIGRIA structures have chiral ligands, which makes the synthesis of these frameworks difficult and expensive. Therefore, these MOFs are excluded. MOCKAR and PEVQAK structures are discarded because defects are encountered (two carbon atoms overlapping instead of double bond, and hydrogen atoms are missing) in the crystallographic information files (CIFs). In the PETWOC structure, the inorganic cluster is $\left[\mathrm{U}_{6} \mathrm{O}_{8}\right]^{12+}$, which contains a radioactive metal, so this structure is also excluded. The structural properties of the MOFs and the results for the mid-density method (step 4) are shown in Table 1. The adsorption isotherms obtained using the mid-density method for each structure are shown in the Supporting Information.

There are three different sets of duplicate structures indicated by superscripts in Table 1 . As mentioned in the previous sections, the treatment of these duplicates is not straightforward. On the basis of the obtained results, it becomes apparent that the corresponding duplicate structures have similar values for the properties $\left(\Delta W_{\text {del }}, L C D, P L D\right.$, adsorption step location) shown in Table 1.

On the basis of the assessed structural properties of the structures, MOFs with unfavorable properties (e.g., difficult/ 
expensive synthesis, etc.) are already discarded. The final selection criteria for choosing the best MOFs are the deliverable working capacity and the location of the adsorption step. The selection is performed by considering the structures in the defined relative pressure intervals (bins) to obtain MOFs for distinctive operating conditions for AC applications. The number of structures in the bins varies greatly. Most of the structures are in the second bin $\left(0.1>p / p_{0}>0.2\right)$, and there is just one in the third $\left(0.2>p / p_{0}>0.3\right)$. There are three structures in the first bin $\left(0.05>p / p_{0}>0.1\right)$ : XAMDUM01 (HKUST-1), YUGLES, and ZIGFEC (Cr-BTC). Among these, the YUGLES structure is chosen because it has the highest deliverable working capacity. The second bin contains 12 structures. Because of the high cardinality of this bin, several structures are chosen with diverse adsorption step locations. The ANUGIA (UMCM-152), SUKYIH, and RUVKAV (PCN46) structures have similar adsorption step locations, and among these, RUVKAV has the highest deliverable working capacity, so this structure is selected. The FUNCEX, HAFTOZ, IRMOF-6, and XEBHOC ( $\mathrm{Cu}_{2}$ (TCPPDA)) structures have also similar step locations. Among them, the HAFTOZ and XEBHOC structures have the highest deliverable working capacity, so these are selected from those five structures. The adsorption uptake step of PEVQEO (IRMOF-1), LAWGEW, and SAHYOQ03 occurs also at similar relative pressures, which is expected because these are duplicates. However, the LAWGEW structure has a slightly higher working capacity; thus, this MOF is selected. In the highest bin, there is just one structure (GUNFAW01) to be selected. The finally selected MOFs are the following: YUGLES $(\mathrm{Cu}), \operatorname{RUVKAV}(\mathrm{Cu}), \operatorname{XEBHOC}(\mathrm{Cu}), \operatorname{HAFTOZ-}$ $(\mathrm{Ni})$, LAWGEW $(\mathrm{Zn})$, and GUNFAW01(Cr, Mn). The methanol isotherms for the six best structures obtained using the mid-density method are shown in Figure 5.

4.2. Screening with Ethanol. In this section, the results of each screening step with ethanol are presented. The calculated methanol and predicted ethanol working capacities (step 1: ethanol) are compared, and it is observed that for most of the structures these values are equal. There are just a few

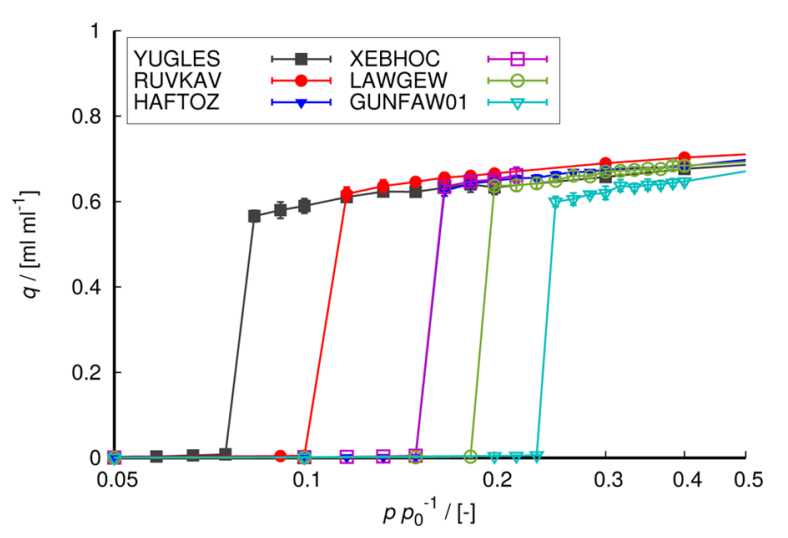

Figure 5. Methanol adsorption isotherms of the six best structures after applying the mid-density method to locate the step location. The excess amounts of adsorbed methanol are shown as a function of relative pressure, $p / p_{0}$ (where $p_{0}$ is the experimentally measured saturation pressure of the adsorbate), at $303 \mathrm{~K}\left(p_{0}=21.70 \mathrm{kPa}\right)^{86}$ for each structure. The error bars indicate the $95 \%$ confidence intervals. The following MOFs can also be referred to with common names: RUVKAV(PCN-46), XEBHOC $\left(\mathrm{Cu}_{2}\right.$ (TCPPDA)), and LAWGEW(IRMOF-1). additional structures (32) with high predicted working capacity ( $>0.4 \mathrm{~mL} \mathrm{~mL}^{-1}$ ) for ethanol, which do not have a high working capacity for methanol (Figure S43 in the Supporting Information). The structures with the predicted working capacity higher than $0.4 \mathrm{~mL} \mathrm{~mL}^{-1}$ are selected for the subsequent screening step. The number of promising structures is reduced to 191 from the initial 2930 without performing any additional simulations.

In Figure 6, the results of the second screening step with both adsorbates are shown. The methanol uptakes are shown

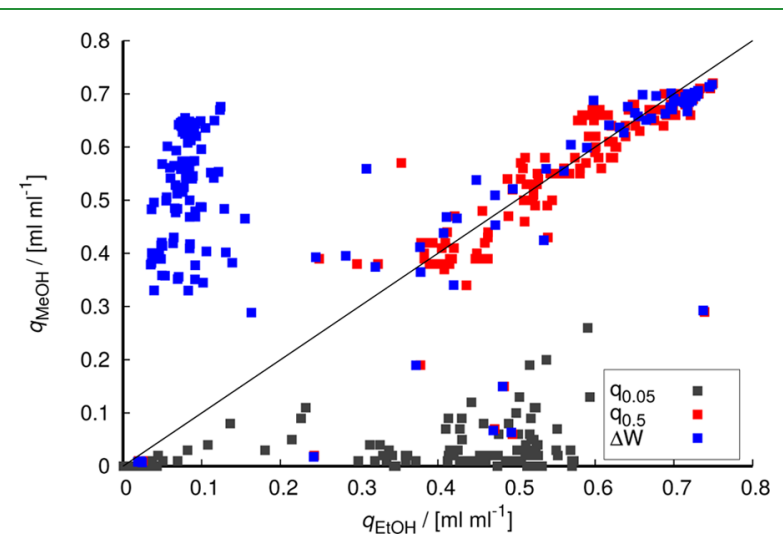

Figure 6. Excess methanol uptakes as a function of excess ethanol uptakes for the ca. 190 structures selected in the first screening step with ethanol. The color code represents the uptake at relative pressures of 0.05 (black) and 0.5 (red) and the working capacity (blue) of the structures.

as a function of the ethanol uptakes. The similar adsorption behavior of the two working fluids can be observed in Figure 6 . A large number of structures show high ethanol and low methanol uptakes at $p / p_{0}=0.5$. These structures are identified as the ones placed in the first bin during the third screening step with methanol. As assumed, the adsorption step for these structures with ethanol is shifted to a lower relative pressure, which results in a high uptake value at $p / p_{0}=0.05$. Consequently, these structures have a low working capacity for ethanol, whereas showing high working capacity for methanol (top left part of Figure 6). At this step (step 2), 55 structures are selected $\left(\Delta W>0.4 \mathrm{~mL} \mathrm{~mL}^{-1}\right)$ for further investigation.

Four more points of the isotherm are calculated for the 55 selected structures at relative pressures of $0.1,0.2,0.3$, and 0.4 . The structures are grouped according to the above-defined bin system. The obtained results also support the assumed similar adsorption behavior of the adsorbates. It is observed that several structures, which are assigned to the third bin with methanol, are placed in the second bin with ethanol. Similarly, there is a significant overlap for the structures in the second bin with methanol and the first with ethanol.

The lack of a steep adsorption step can also be observed with ethanol. After obtaining the additional isotherm points, the deliverable working capacity for numerous structures (10) becomes lower than the desired $0.4 \mathrm{~mL} \mathrm{~mL}^{-1}$. These structures are not considered further.

On the basis of structural properties, MOFs with unfavorable attributes (e.g., difficult or expensive synthesis, containing potentially harmful building blocks, flexibility of the framework, etc.) for application in ACs are discarded. Because the flexibility of the framework can cause desorption 
hysteresis, $^{13}$ the flexible MIL-88c-open structure is not considered for further investigation. Furthermore, as the RONZID, JUTCUW, and PIYZAZ structures contain cyanide, which is a potentially harmful substance, these MOFs are discarded. The VUSJUP structure is excluded because of a defect in the reported structure (CIF). Among the chosen structures, there are numerous duplicates from which the one with the highest deliverable working capacity is selected. After the structural analysis and the selection based on deliverable working capacity are performed (step 3), the number of remaining structures is 12 . Eight structures are selected from the first, three from the second, one from the third, and zero from the fourth bin.

The structural properties and results after performing the mid-density analysis with the five additional adsorption uptakes (step 4) are shown in Table S3 in the Supporting Information. The structures are regrouped because of the shift in the location of the adsorption step, and structures with high deliverable working capacity are chosen from the distinctive bins. The ANUGIA and RUVKAV structures show the adsorption step below the lower limit of the first bin. The deviation from the lower limit is small compared with the size of the bin (10\%). Hence, on the basis of the deliverable working capacity values, the RUVKAV structure is considered as a promising candidate. From the first bin, the FUNBOG, $\mathrm{XEBHOC}$, and PEVQEO structures are chosen because of their high working capacity and diverse step location. In the second and third bins, only one structure is placed at the last selection step. Both of these structures are considered promising frameworks. Therefore, the finally selected frameworks are the following: $\operatorname{RUVKAV}(\mathrm{Cu}), \operatorname{FUNBOG}(\mathrm{Zn})$, $\operatorname{XEBHOC}(\mathrm{Cu})$, PEVQEO(Zn), HAFTOZ $(\mathrm{Ni})$, and GUNFAW01(Cr, Mn). The ethanol isotherms for the best six structures after applying the mid-density method are shown in Figure 7.

By conducting four subsequent screening steps, six structures with both working fluids are selected. The selected structures show considerably high deliverable working capacities and diverse adsorption step locations with both

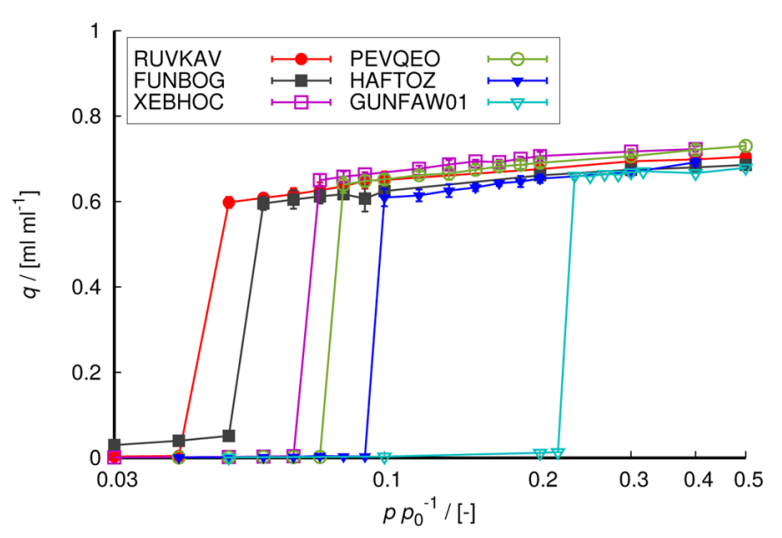

Figure 7. Ethanol adsorption isotherms of the six best structures after applying the mid-density method to locate the step location. The excess amounts of adsorbed ethanol are shown as a function of relative pressure, $p / p_{0}$ (where $p_{0}$ is the experimentally measured saturation pressure of the adsorbate), at $303 \mathrm{~K}\left(p_{0}=10.38 \mathrm{kPa}\right)^{86}$ for each structure. The error bars indicate the $95 \%$ confidence intervals. The following MOFs can also be referred to with common names: RUVKAV(PCN-46), XEBHOC $\left(\mathrm{Cu}_{2}(\mathrm{TCPPDA})\right)$, and PEVQEO(IRMOF-1). working fluids. For the two working fluids, five of the selected structures are the same (PEVQEO and LAWGEW are duplicates), which supports the assumption for the similar adsorption behavior of the two working fluids. The sixth bestperforming candidate selected is YUGLES for methanol and FUNBOG for ethanol. Because all structures in the database are experimentally synthesized, the synthesis route and characterization of the most promising MOFs are available in the literature. ${ }^{64-70}$ For most of the selected structures, experimentally measured adsorption isotherms with several adsorbates (e.g., $\mathrm{H}_{2}, \mathrm{~N}_{2}, \mathrm{CO}_{2}$, etc.) are reported. ${ }^{64-66,68,71-74}$

It can be seen that the selected structures have diverse cluster and linker types with several types of metal ions $(\mathrm{Cu}$, $\mathrm{Zn}, \mathrm{Ni}, \mathrm{Cr}, \mathrm{Mn}$ ). The atomistic representations of the seven different selected MOFs are shown in Figure 8. Despite the differences in cluster and linker types, the selected structures have several similar physical properties. All frameworks have high helium void fractions and volumetric surface areas and similar pore dimensions, as shown in Tables 1 and S3 in the Supporting Information. In Figures S45 and S46 in the Supporting Information, the deliverable working capacities of the best 25 structures with methanol are shown as a function of volumetric surface area (VSA) and helium void fraction. It can be observed that with increasing VSA and helium void fraction the deliverable working capacity increases; however, a correlation based on only these properties cannot be established. In Figure 3c, several structures with high helium void fraction and low maximum working capacity are shown, which suggests that considering only the physical properties (helium void fraction, surface area, pore dimension) of the structures is not sufficient to predict the deliverable working capacity of the framework. Because electrostatic interactions play a major role in the adsorption of polar adsorbates in MOFs, the polarity of the linkers also needs to be taken into account at the assessment of MOFs for AC application.

The YUGLES $(\mathrm{Cu})$ and $\operatorname{RUVKAV}(\mathrm{Cu})$ (see the isotherm in Figures S32 and S39 in the Supporting Information) structures differ only in the length of the linkers connecting the metal clusters. While the small difference in the length of the linkers (two carbon atoms) does not have a significant effect on the polarity of the pores, it leads to a larger pore size for the RUVKAV framework. Therefore, the two structures have similar adsorption affinity but the RUVKAV framework can accommodate a higher amount of working fluid. For the RUVKAV structure, the adsorption step occurs at a higher relative pressure because more working fluid is required for pore condensation. It is expected that by further increasing the size of the linker, without the incorporation of polar functionalities, the volumetric working capacity of the framework would be reduced because of the weaker interaction between the MOF and the working fluid. Although the incorporation of polar functionalities can increase the volumetric working capacity, it also increases the adsorption affinity, which may lead to stronger interactions between the framework and adsorbate. This may cause undesirably high desorption temperatures. Our results indicate that the pore dimensions and the polarity of linkers have a combined effect on the adsorption of polar adsorbates in MOFs. Nevertheless, for establishing rigorous correlations between these properties and the deliverable working capacity, further research is necessary. 


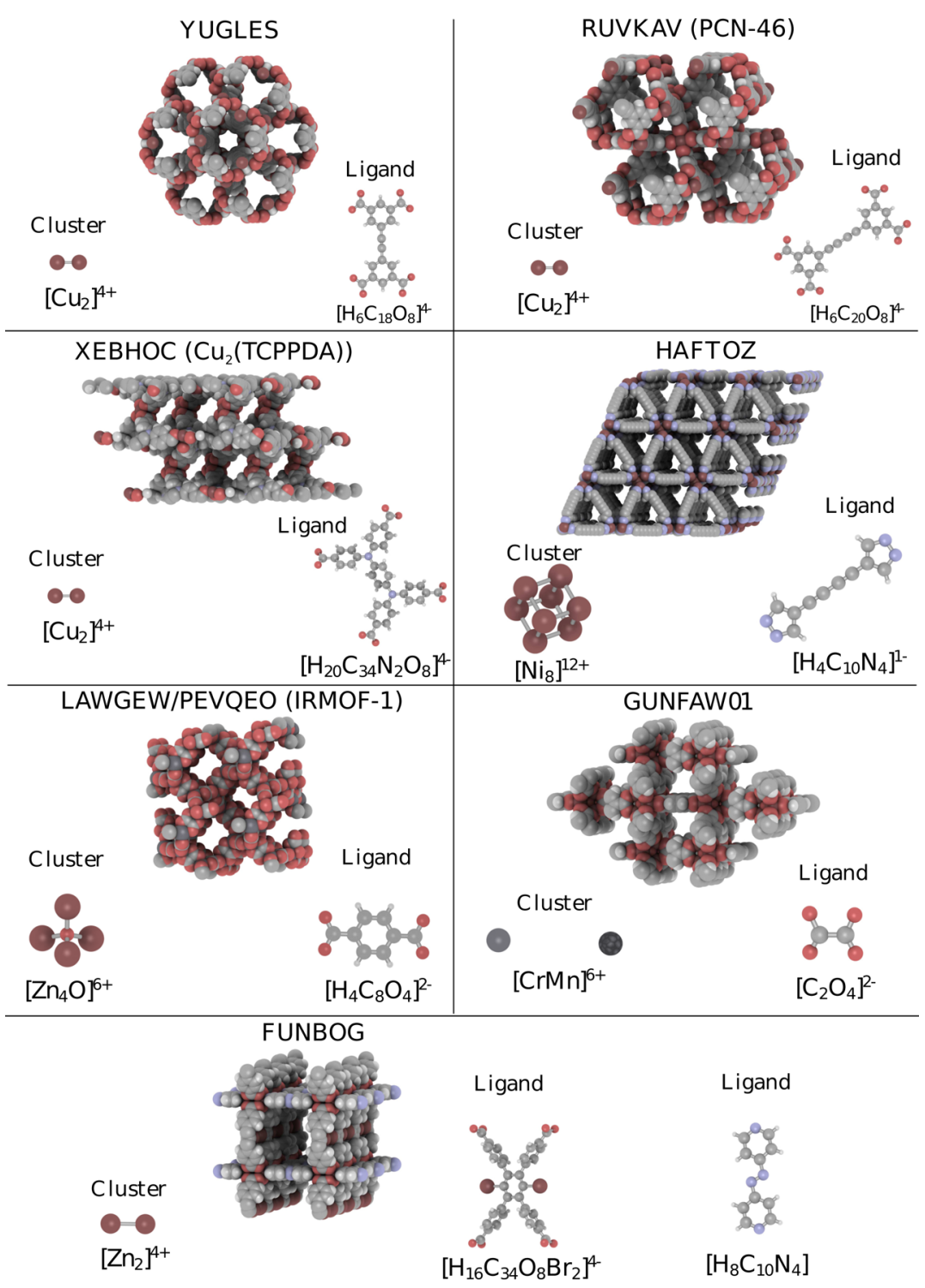

Figure 8. Atomistic representation of the finally selected structures. The super cell, cluster, and linker are shown for each finally selected MOF. Because the LAWGEW and PEVQEO structures are duplicates, this MOF is shown only once. The following MOFs can also be referred to with common names: $\operatorname{RUVKAV}(\mathrm{PCN}-46)$, $\mathrm{XEBHOC}\left(\mathrm{Cu}_{2}(\mathrm{TCPPDA})\right)$, and LAWGEW(IRMOF-1). The graphical representation is created with iRASPA. ${ }^{87}$

\section{CONCLUSIONS}

A computational screening of $\sim 2930$ experimentally synthesized metal-organic frameworks is performed to find the bestperforming structures for AC applications with methanol and ethanol as working fluids. To the best of our knowledge, this is the first reported computational screening study of MOFs involving the phenomenon of pore condensation to date. The screening procedure with methanol is performed in four subsequent steps. On the basis of the obtained results in the first three screening steps for methanol, it is concluded that for the investigated pore size range the adsorbents can be assumed to be saturated at relative pressure $p / p_{0}=0.5$. Therefore, the loading at relative pressure $p / p_{0}=0.05$ determines the maximum working capacity for AC application. It is observed that the helium void fraction of the structure is a reasonable descriptor of the maximum working capacity. In the fourth step of the screening process, the mid-density scheme ${ }^{55}$ is applied to efficiently and accurately locate the position of the adsorption step (equilibrium phase transition). By using the results obtained in the first and second steps of the screening with methanol, the screening process for ethanol is commenced. It is found that by assuming a similar adsorption behavior for methanol and ethanol a significant amount of calculations can be avoided. Without performing any additional simulations, just by considering the results obtained for methanol, the number of possible candidate structures is reduced from 2930 to ca. 190. In a similar manner as for methanol, four subsequent steps are carried out for ethanol. At the end of the screening procedure, the six most promising structures are selected on the basis of the location of the adsorption step and deliverable working capacity with both working fluids (see Figures 5 and 7 ). These structures are considered promising for $\mathrm{AHP} / \mathrm{AC}$ application because the deliverable working capacities are considerably higher $(\sim 0.6$ $\left.\mathrm{mL} \mathrm{mL}^{-1}\right)$ than the previously reported highest value $(\sim 0.45$ $\left.\mathrm{mL} \mathrm{mL}^{-1}\right)$ in the literature. ${ }^{32}$ It is shown that the screening of MOFs with methanol and ethanol for AHP/AC applications is 
a challenging task but it can be performed with a reasonable amount of computational effort. These results can provide fundamental guidance for experimental and computational investigations of new MOFs for AHP/AC application.

\section{ASSOCIATED CONTENT}

\section{(5) Supporting Information}

The Supporting Information is available free of charge on the ACS Publications website at DOI: 10.1021/acsami.8b09343.

Lennard-Jones parameters for the framework atoms;force field parameters for methanol and ethanol; experimental and simulation results of adsorbed methanol and ethanol (PDF)

\section{AUTHOR INFORMATION}

\section{Corresponding Author}

*E-mail: t.j.h.vlugt@tudelft.nl.

\section{ORCID $\odot$}

Freek Kapteijn: 0000-0003-0575-7953

Othonas A. Moultos: 0000-0001-7477-9684

Thijs J. H. Vlugt: 0000-0003-3059-8712

\section{Notes}

The authors declare no competing financial interest.

\section{ACKNOWLEDGMENTS}

This work was sponsored by NWO Exacte Wetenschappen (Physical Sciences) for the use of supercomputer facilities. The authors also gratefully acknowledge the financial support from The Netherlands Research Council for Chemical Sciences (NWO/CW) through a VICI grant (T.J.H.V.) and the Advanced Dutch Energy Materials (ADEM) program of the Dutch Ministry of Economic Affairs, Agriculture, and Innovation.

\section{REFERENCES}

(1) EIA. International Energy Outlook, 2018. Available at http:// www.eia.gov/outlooks/ieo/pdf/0484(2016).pdf.

(2) European Comission. Communication from the commission to the European Parliament, the Council, the European Economic and Social committee and the committe of the regions, 2018. Available at https://ec.europa.eu/energy/sites/ener/files/documents/1_EN_ ACT_part1_v14.pdf.

(3) Isaac, $\bar{M}$.; van Vuuren, D. P. Modeling global residential sector energy demand for heating and air conditioning in the context of climate change. Energy Policy 2009, 37, 507-521.

(4) Tatsidjodoung, P.; Le Pierrés, N.; Luo, L. A review of potential materials for thermal energy storage in building applications. Renewable Sustainable Energy Rev. 2013, 18, 327-349.

(5) Aneke, M.; Wang, M. Energy storage technologies and real life applications - A state of the art review. Appl. Energy 2016, 179, 350377.

(6) Moran, M. J.; Shapiro, H. N. Fundamentals of Engineering Thermodynamics, 5th ed.; Wiley: New York, 2006.

(7) Parham, K.; Khamooshi, M.; Tematio, D. B. K.; Yari, M.; Atikol, $\mathrm{U}$. Absorption heat transformers - A comprehensive review. Renewable Sustainable Energy Rev. 2014, 34, 430-452.

(8) Chan, C. W.; Ling-Chin, J.; Roskilly, A. P. A review of chemical heat pumps, thermodynamic cycles and thermal energy storage technologies for low grade heat utilisation. Appl. Therm. Eng. 2013, 50, 1257-1273.

(9) Aristov, Y. I. Challenging offers of material science for adsorption heat transformation: A review. Appl. Therm. Eng. 2013, 50, 1610-1618.
(10) Younes, M. M.; El-Sharkawy, I. I.; Kabeel, A. E.; Saha, B. B. A review on adsorbent-adsorbate pairs for cooling applications. Appl. Therm. Eng. 2017, 114, 394-414.

(11) Henning, H.-M. Solar assisted air conditioning of buildings - an overview. Appl. Therm. Eng. 2007, 27, 1734-1749.

(12) Santori, G.; Di Santis, C. Optimal fluids for adsorptive cooling and heating. Sustainable Mater. Technol. 2017, 12, 52-61.

(13) De Lange, M. F.; Verouden, K. J. F. M.; Vlugt, T. J. H.; Gascon, J.; Kapteijn, F. Adsorption-Driven Heat Pumps: The Potential of Metal-Organic Frameworks. Chem. Rev. 2015, 115, 12205-12250.

(14) Ugale, V. D.; Pitale, A. D. A review on working pair used in adsorption cooling system. Int. J. Air-Cond. Refrig. 2015, 23, No. 1530001

(15) Wang, D.; Zhang, J.; Yang, Q.; Li, N.; Sumathy, K. Study of adsorption characteristics in silica gel-water adsorption refrigeration. Appl. Energy 2014, 113, 734-741.

(16) Zhou, H.-C. J.; Kitagawa, S. Metal-Organic Frameworks (MOFs). Chem. Soc. Rev. 2014, 43, 5415-5418.

(17) Moghadam, P. Z.; Li, A.; Wiggin, S. B.; Tao, A.; Maloney, A. G. P.; Wood, P. A.; Ward, S. C.; Fairen-Jimenez, D. Development of a Cambridge Structural Database Subset: A Collection of MetalOrganic Frameworks for Past, Present, and Future. Chem. Mater. 2017, 29, 2618-2625.

(18) Furukawa, H.; Cordova, K. E.; O’Keeffe, M.; Yaghi, O. M. The chemistry and applications of Metal-Organic Frameworks. Science 2013, 341, No. 1230444.

(19) McGuire, C. V.; Forgan, R. S. The surface chemistry of metalorganic frameworks. Chem. Commun. 2015, 51, 5199-5217.

(20) Kitagawa, S.; Kitaura, R.; Noro, S.-I. Functional porous coordination polymers. Angew. Chem., Int. Ed. 2004, 43, 2334-2375.

(21) Li, J.-R.; Kuppler, R. J.; Zhou, H.-C. Selective gas adsorption and separation in metal-organic frameworks. Chem. Soc. Rev. 2009, 38, $1477-1504$.

(22) Henninger, S. K.; Jeremias, F.; Kummer, H.; Janiak, C. MOFs for use in adsorption heat pump processes. Eur. J. Inorg. Chem. 2012, $2625-2634$.

(23) De Lange, M. F.; Van Velzen, B. L.; Ottevanger, C. P.; Verouden, K. J. F. M.; Lin, L.-C.; Vlugt, T. J. H.; Gascon, J.; Kapteijn, F. Metal-Organic Frameworks in Adsorption-Driven Heat Pumps: The Potential of Alcohols as Working Fluids. Langmuir 2015, 31, 12783-12796.

(24) Saha, D.; Deng, S. Ammonia adsorption and its effects on framework stability of MOF-5 and MOF-177. J. Colloid Interface Sci. 2010, 348, 615-620.

(25) Burtch, N. C.; Jasuja, H.; Walton, K. S. Water stability and adsorption in metal-organic frameworks. Chem. Rev. 2014, 114, 10575-10612.

(26) Jeremias, F.; Fröhlich, D.; Janiak, C.; Henninger, S. K. Water and methanol adsorption on MOFs for cycling heat transformation processes. New J. Chem. 2014, 38, 1846-1852.

(27) Sato, H.; Watanabe, K.; Levelt Sengers, J. M. H.; Gallagher, J. S.; Hill, P. G.; Straub, J.; Wagner, W. Sixteen Thousand Evaluated Experimental Thermodynamic Property Data for Water and Steam. J. Phys. Chem. Ref. Data 1991, 20, 1023-1044.

(28) Brown, G.N.; Ziegler, W. T. Temperature Dependence of Excess Thermodynamic Properties of Ethanol $+\mathrm{n}$-Heptane and 2Propanol + n-Heptane Solutions. J. Chem. Eng. Data 1979, 24, 319330.

(29) Carlson, H. G.; Westrum, E. F., Jr. Methanol: Heat capacity, enthalpies of transition and melting, and thermodynamic properties from 5-300 K. J. Chem. Phys. 1971, 54, 1464-1471.

(30) Critoph, R. E.; Zhong, Y. Review of trends in solid sorption refrigeration and heat pumping technology. Proc. Inst. Mech. Eng., Part E 2005, 219, 285-300.

(31) Green, D. W.; Perry, R. H. Perry's Chemical Engineers' Handbook, 8th ed.; McGraw-Hill: New York, 2008.

(32) Nguyen, B. T.; Nguyen, H. L.; Nguyen, T. C.; Cordova, K. E.; Furukawa, H. High Methanol Uptake Capacity in Two New Series of 
Metal-Organic Frameworks: Promising Materials for AdsorptionDriven Heat Pump Applications. Chem. Mater. 2016, 28, 6243-6249. (33) Sun, W.; Lin, L.-C.; Peng, X.; Smit, B. Computational screening of porous metal-organic frameworks and zeolites for the removal of $\mathrm{SO}_{2}$ and $\mathrm{NO}_{\mathrm{x}}$ from flue gases. AIChE J. 2014, 60, 2314-2323.

(34) Erucar, I.; Keskin, S. Screening metal-organic framework-based mixed-matrix membranes for $\mathrm{CO}_{2} / \mathrm{CH}_{4}$ separations. Ind. Eng. Chem. Res. 2011, 50, 12606-12616.

(35) Haldoupis, E.; Nair, S.; Sholl, D. S. Finding MOFs for highly selective $\mathrm{CO}_{2} / \mathrm{N}_{2}$ adsorption using materials screening based on efficient assignment of atomic point charges. J. Am. Chem. Soc. 2012, 134, 4313-4323.

(36) Chung, Y. G.; Bai, P.; Haranczyk, M.; Leperi, K. T.; Li, P.; Zhang, H.; Wang, T. C.; Duerinck, T.; You, F.; Hupp, J. T.; Farha, O. K.; Siepmann, J. I.; Snurr, R. Q. Computational Screening of Nanoporous Materials for Hexane and Heptane Isomer Separation. Chem. Mater. 2017, 29, 6315-6328.

(37) Altintas, C.; Erucar, I.; Keskin, S. High-Throughput Computational Screening of the Metal Organic Framework Database for $\mathrm{CH}_{4} /$ $\mathrm{H}_{2}$ Separations. ACS Appl. Mater. Interfaces 2018, 10, 3668-3679.

(38) Chung, Y. G.; Gómez-Gualdrón, D. A.; Li, P.; Leperi, K. T.; Deria, P.; Zhang, H.; Vermeulen, N. A.; Stoddart, J. F.; You, F.; Hupp, J. T.; Farha, O. K.; Snurr, R. Q. In silico discovery of metal-organic frameworks for precombustion $\mathrm{CO}_{2}$ capture using a genetic algorithm. Sci. Adv. 2016, 2, No. e1600909.

(39) Zhang, H.; Bucior, B. J.; Snurr, R. Q. Molecular Modeling of Carbon Dioxide Adsorption in Metal-Organic Frameworks. Modell. Simul. Sci. Micro- Meso-Porous Mater. 2017, 99-149.

(40) Colón, Y. J.; Snurr, R. Q. High-throughput computational screening of metal-organic frameworks. Chem. Soc. Rev. 2014, 43, $5735-5749$.

(41) Bao, X.; Broadbelt, L. J.; Snurr, R. Q. Computational screening of homochiral metal-organic frameworks for enantioselective adsorption. Microporous Mesoporous Mater. 2012, 157, 118-123.

(42) Chung, Y. G.; Camp, J.; Haranczyk, M.; Sikora, B. J.; Bury, W.; Krungleviciute, V.; Yildirim, T.; Farha, O. K.; Sholl, D. S.; Snurr, R. Q. Computation-Ready, Experimental Metal-Organic Frameworks: A Tool To Enable High-Throughput Screening of Nanoporous Crystals. Chem. Mater. 2014, 26, 6185-6192.

(43) Nazarian, D.; Camp, J. S.; Sholl, D. S. A Comprehensive Set of High-Quality Point Charges for Simulations of Metal-Organic Frameworks. Chem. Mater. 2016, 28, 785-793.

(44) Karra, J. R.; Walton, K. Effect of open metal sites on adsorption of polar and nonpolar molecules in metal-organic framework $\mathrm{Cu}$ BTC. Langmuir 2008, 24, 8620-8626.

(45) Thornton, A. W.; Simon, C. M.; Kim, J.; Kwon, O.; Deeg, K. S.; Konstas, K.; Pas, S. J.; Hill, M. R.; Winkler, D. A.; Haranczyk, M.; Smit, B. Materials Genome in Action: Identifying the Performance Limits of Physical Hydrogen Storage. Chem. Mater. 2017, 29, 28442854.

(46) Bobbitt, N. S.; Chen, J.; Snurr, R. Q. High-Throughput Screening of Metal-Organic Frameworks for Hydrogen Storage at Cryogenic Temperature. J. Phys. Chem. C 2016, 120, 27328-27341.

(47) Qiao, Z.; Peng, C.; Zhou, J.; Jiang, J. High-throughput computational screening of 137953 metal-organic frameworks for membrane separation of a $\mathrm{CO}_{2} / \mathrm{N}_{2} / \mathrm{CH}_{4}$ mixture. J. Mater. Chem. A 2016, 4, 15904-15912.

(48) Simon, C. M.; Kim, J.; Gomez-Gualdron, D. A.; Camp, J. S.; Chung, Y. G.; Martin, R. L.; Mercado, R.; Deem, M. W.; Gunter, D.; Haranczyk, M.; Sholl, D. S.; Snurr, R. Q.; Smit, B. The materials genome in action: Identifying the performance limits for methane storage. Energy Environ. Sci. 2015, 8, 1190-1199.

(49) Gomez, D. A.; Toda, J.; Sastre, G. Screening of hypothetical metal-organic frameworks for $\mathrm{H} 2$ storage. Phys. Chem. Chem. Phys. 2014, 16, 19001-19010.

(50) Wilmer, C. E.; Leaf, M.; Lee, C. Y.; Farha, O. K.; Hauser, B. G.; Hupp, J. T.; Snurr, R. Q. Large-scale screening of hypothetical metalorganic frameworks. Nat. Chem. 2012, 4, 83-89.
(51) Lin, L.-C.; Berger, A. H.; Martin, R. L.; Kim, J.; Swisher, J. A.; Jariwala, K.; Rycroft, C. H.; Bhown, A. S.; Deem, M. W.; Haranczyk, M.; Smit, B. In silico screening of carbon-capture materials. Nat. Mater. 2012, 11, 633-641.

(52) Becker, T. M.; Heinen, J.; Dubbeldam, D.; Lin, L.-C.; Vlugt, T. J. H. Polarizable Force Fields for $\mathrm{CO}_{2}$ and $\mathrm{CH}_{4}$ Adsorption in $\mathrm{M}$ MOF-74. J. Phys. Chem. C 2017, 121, 4659-4673.

(53) Becker, T. M.; Dubbeldam, D.; Lin, L.-C.; Vlugt, T. J. H. Investigating polarization effects of $\mathrm{CO}_{2}$ adsorption in MgMOF-74. J. Comput. Sci. 2016, 15, 86-94.

(54) Lemmon, E. W.; McLinden, M. O.; Friend, D. G. In "Thermophysical Properties of Fluid Systems" in NIST Chemistry WebBook, NIST Standard Reference Database Number 69; Linstrom, P. J., Mallard, W. G., Eds.; National Institute of Standards and Technology: Gaithersburg, 2005.

(55) Liu, Z.; Herrera, L.; Nguyen, V. T.; Do, D. D.; Nicholson, D. A Monte Carlo scheme based on mid-density in a hysteresis loop to determine equilibrium phase transition. Mol. Simul. 2011, 37, 932939.

(56) Dubbeldam, D.; Torres-Knoop, A.; Walton, K. S. On the inner workings of Monte Carlo codes. Mol. Simul. 2013, 39, 1253-1292.

(57) Dubbeldam, D.; Calero, S.; Ellis, D. E.; Snurr, R. Q. RASPA: Molecular simulation software for adsorption and diffusion in flexible nanoporous materials. Mol. Simul. 2016, 42, 81-101.

(58) Allen, M. P.; Tildesley, D. J. Computer Simulation of Liquids, 2nd ed.; Oxford University Press: New York, 2017.

(59) Vlugt, T. J. H.; Schenk, M. Influence of framework flexibility on the adsorption properties of hydrocarbons in the zeolite silicalite. $J$. Phys. Chem. B 2002, 106, 12757-12763.

(60) Frenkel, D.; Smit, B. Understanding Molecular Simulation, 2nd ed.; Academic Press: London, 2001.

(61) Martin, R. L.; Smit, B.; Haranczyk, M. Addressing Challenges of Identifying Geometrically Diverse Sets of Crystalline Porous Materials. J. Chem. Inf. Model. 2012, 52, 308-318.

(62) Peterson, B. K.; Gubbins, K. E. Phase transitions in a cylindrical pore grand canonical monte carlo, mean field theory and the kelvin equation. Mol. Phys. 1987, 62, 215-226.

(63) Maris, T.; Vlugt, T. J. H.; Smit, B. Simulation of alkane adsorption in the aluminophosphate molecular sieve AlPO4-5. J. Phys. Chem. B 1998, 102, 7183-7189.

(64) Hu, Y.; Xiang, S.; Zhang, W.; Zhang, Z.; Wang, L.; Bai, J.; Chen, B. A new MOF-505 analog exhibiting high acetylene storage. Chem. Commun. 2009, 7551-7553.

(65) Zhao, D.; Yuan, D.; Yakovenko, A.; Zhou, H.-C. A NbO-type metal-organic framework derived from a polyyne-coupled diisophthalate linker formed in situ. Chem. Commun. 2010, 46, 41964198.

(66) Sun, D.; Ke, Y.; Mattox, T. M.; Ooro, B. A.; Zhou, H.-C. Temperature-dependent supramolecular stereoisomerism in porous copper coordination networks based on a designed carboxylate ligand. Chem. Commun. 2005, 5447-5449.

(67) Quartapelle Procopio, E.; Rojas, S.; Padial, N. M.; Galli, S.; Masciocchi, N.; Linares, F.; Miguel, D.; Oltra, J. E.; Navarro, J. A. R.; Barea, E. Study of the incorporation and release of the nonconventional half-sandwich ruthenium(ii) metallodrug RAPTA-C on a robust MOF. Chem. Commun. 2011, 47, 11751-11753.

(68) Eddaoudi, M.; Kim, J.; Rosi, N.; Vodak, D.; Wachter, J.; O'Keeffe, M.; Yaghi, O. Systematic design of pore size and functionality in isoreticular MOFs and their application in methane storage. Science 2002, 295, 469-472.

(69) Andrés, R.; Brissard, M.; Gruselle, M.; Train, C.; Vaissermann, J.; Malézieux, B.; Jamet, J.-P.; Verdaguer, M. Rational design of threedimensional (3D) optically active molecule-based magnets. Inorg. Chem. 2001, 40, 4633-4640.

(70) Farha, O. K.; Malliakas, C. D.; Kanatzidis, M. G.; Hupp, J. T. Control over catenation in metal-organic frameworks via rational design of the organic building block. J. Am. Chem. Soc. 2010, 132, 950-952. 
(71) Suh, M. P.; Park, H. J.; Prasad, T. K.; Lim, D.-W. Hydrogen storage in metal-organic frameworks. Chem. Rev. 2012, 112, 782-835.

(72) Liang, Z.; Du, J.; Sun, L.; Xu, J.; Mu, Y.; Li, Y.; Yu, J.; Xu, R. Design and synthesis of two porous metal-organic frameworks with nbo and agw topologies showing high $\mathrm{CO}_{2}$ adsorption capacity. Inorg. Chem. 2013, 52, 10720-10722.

(73) Padial, N. M.; Quartapelle Procopio, E.; Montoro, C.; López, E.; Oltra, J. E.; Colombo, V.; Maspero, A.; Masciocchi, N.; Galli, S.; Senkovska, I.; Kaskel, S.; Barea, E.; Navarro, J. A. R. Highly hydrophobic isoreticular porous metal-organic frameworks for the capture of harmful volatile organic compounds. Angew. Chem., Int. Ed. 2013, 52, 8290-8294.

(74) Rowsell, J. L. C.; Spencer, E. C.; Eckert, J.; Howard, J. A. K.; Yaghi, O. Chemistry: Gas adsorption sites in a large-pore metalorganic framework. Science 2005, 309, 1350-1354.

(75) Graham, A. J.; Tan, J.-C.; Allan, D. R.; Moggach, S. A. The effect of pressure on Cu-BTC: Framework compression vs. guest inclusion. Chem. Commun. 2012, 48, 1535-1537.

(76) Murray, L. J.; Dinca, M.; Yano, J.; Chavan, S.; Bordiga, S.; Brown, C. M.; Long, J. R. Highly-selective and reversible $\mathrm{O}_{2}$ binding in $\mathrm{Cr}_{3}(1,3,5 \text {-benzenetricarboxylate })_{2}$. J. Am. Chem. Soc. 2010, 132, $7856-7857$.

(77) Schnobrich, J. K.; Lebel, O.; Cychosz, K.; Dailly, A.; Wong-Foy, A.; Matzger, A. Linker-directed vertex desymmetrization for the production of coordination polymers with high porosity. J. Am. Chem. Soc. 2010, 132, 13941-13948.

(78) Ma, L.; Jin, A.; Xie, Z.; Lin, W. Freeze drying significantly increases permanent porosity and hydrogen uptake in 4,4-connected metal-organic frameworks. Angew. Chem. 2009, 48, 10089-10092.

(79) Wei, Y.-S.; Chen, K.-J.; Liao, P.-Q.; Zhu, B.-Y.; Lin, R.-B.; Zhou, H.-L.; Wang, B.-Y.; Xue, W.; Zhang, J.-P.; Chen, X.-M. Turning on the flexibility of isoreticular porous coordination frameworks for drastically tunable framework breathing and thermal expansion. Chem. Sci. 2013, 4, 1539-1546.

(80) Jia, J.; Lin, X.; Wilson, C.; Blake, A. J.; Champness, N. R.; Hubberstey, P.; Walker, G.; Cussen, E. J.; Schröder, M. Twelveconnected porous metal-organic frameworks with high $\mathrm{H}_{2}$ adsorption. Chem. Commun. 2007, 840-842.

(81) Eddaoudi, M.; Kim, J.; Vodak, D.; Sudik, A.; Wachter, J.; O'Keeffe, M.; Yaghi, O. M. Geometric requirements and examples of important structures in the assembly of square building blocks. Proc. Natl. Acad. Sci. U.S.A. 2002, 99, 4900-4904.

(82) Dybtsev, D. N.; Chun, H.; Kim, K. Rigid and flexible: A highly porous metal-organic framework with unusual guest-dependent dynamic behavior. Angew. Chem., Int. Ed. 2004, 43, 5033-5036.

(83) Feng, L.; Chen, Z.; Liao, T.; Li, P.; Jia, Y.; Liu, X.; Yang, Y.; Zhou, Y. Supramolecular isomerism of metal-organic frameworks derived from a bicarboxylate linker with two distinct binding motifs. Cryst. Growth Des. 2009, 9, 1505-1510.

(84) Kitazawa, T.; Nishikiori, S.; Iwamoto, T. Three-dimensional framework structures built of heptacyanotricadmate(II) units providing polyhedral cavities for guests: Classification of the zeolitelike structures. J. Chem. Soc., Dalton Trans. 1994, 3695-3710.

(85) Neofotistou, E.; Malliakas, C. D.; Trikalitis, P. N. Remarkable structural diversity and single-crystal-to-single-crystal transformations in sulfone functionalized lanthanide MOFs. CrystEngComm 2010, 12, 1034-1037.

(86) Ambrose, D.; Sprake, C. H. S. Thermodynamic properties of organic oxygen compounds XXV. Vapour pressures and normal boiling temperatures of aliphatic alcohols. J. Chem. Thermodyn. 1970, 2, 631-645.

(87) Dubbeldam, D.; Calero, S.; Vlugt, T. J. H. iRASPA: GPUaccelerated visualization software for materials scientists. Mol. Simul. 2018, 44, 653-676. 